Keywords: long-term survivors; short-term survivors; metastatic breast cancer; HER2-positive; registHER; latent class modelling (LCM)

\title{
Long-term survivor characteristics in HER2-positive metastatic breast cancer from registHER
}

D A Yardley ${ }^{*}, 1$, D Tripathy ${ }^{2}$, A M Brufsky ${ }^{3}$, H S Rugo ${ }^{4}$, P A Kaufman ${ }^{5}$, M Mayer $^{6}, \mathrm{~J} \mathrm{Magidson}^{7}$, B Yoo $^{8}, \mathrm{C} \mathrm{Ouah}^{8}$ and M Ulcickas Yood ${ }^{9,10}$

${ }^{1}$ Sarah Cannon Research Institute/Tennessee Oncology, PLLC, 250 25th Avenue N, Ste 100 Nashville, TN 37203, USA; ${ }^{2}$ Keck School of Medicine, University of Southern California, 1441 Eastlake Avenue, Los Angeles, CA 90033, USA; ${ }^{3}$ University of Pittsburgh Cancer Institute, 200 Lothrop Street, Pittsburgh, PA 15213, USA; ${ }^{4}$ University of California, San Francisco, Helen Diller Family Comprehensive Cancer Center, 1600 Divisadero Street, San Francisco, CA 94115, USA; ${ }^{5}$ Norris Cotton Cancer Center, Dartmouth-Hitchcock Medical Center, One Medical Center Dr, Lebanon, NH 03756, USA; ${ }^{6}$ AdvancedBC.org 250 West 82 Street, \#42, New York, NY 10024, USA; ${ }^{7}$ Statistical Innovations Inc, 375 Concord Avenue, Belmont, MA 02478, USA; ${ }^{8}$ Genentech, Inc., 1 DNA Way, South San Francisco, CA 94080, USA; ${ }^{9}$ EpiSource, LLC, 53 Fenwick Road, Waban, MA 02468, USA and ${ }^{10}$ Boston University School of Medicine, 72 East Concord Street, Boston, MA 02118, USA

Background: Data characterising long-term survivors (LTS) with human epidermal growth factor receptor 2 (HER2)-positive metastatic breast cancer (MBC) are limited. This analysis describes LTS using registHER observational study data.

Methods: A latent class modelling (LCM) approach was used to identify distinct homogenous patient groups (or classes) based on progression-free survival (PFS), overall survival, and complete response. Demographics, clinicopathologic factors, first-line treatment patterns, and clinical outcomes were described for each class. Class-associated factors were evaluated using logistic regression analysis.

Results: LCM identified two survivor groups labelled as LTS $(n=244)$ and short-term survivors (STS; $n=757)$. Baseline characteristics were similar between groups, although LTS were more likely to be white (83.6\% vs $77.8 \%$ ) with oestrogen receptorpositive (ER +) or progesterone receptor-positive (PgR +) disease (59.4\% vs 50.9\%). Median PFS in LTS was 37.2 (95\% confidence interval (Cl): $32.9-40.5)$ vs 7.3 months (95\% Cl: 6.8-8.0) in STS. Factors associated with long-term survival included ER + or PgR + disease, metastasis to node/local sites, first-line trastuzumab use, and first-line taxane use.

Conclusions: Prognostic variables identified by LCM define a HER2-positive MBC patient profile and therapies that may be associated with more favourable long-term outcomes, enabling treatment selection appropriate to the patient's disease characteristics.

Breast cancer is the leading cause of cancer-related death in women, with $\sim 40000$ US women expected to die from this disease in 2013 (Siegel et al, 2013). Amplification of the human epidermal growth factor receptor 2 (HER2) gene occurs in approximately $20 \%$ of patients with breast cancer (Ross et al, 2009; Dawood et al, 2010a), and this molecular subtype is associated with poor prognostic factors as shown by its highly proliferative and often high-grade histology (Eroles et al, 2012). In addition, patients with HER2-positive disease are more likely to develop central nervous system and visceral metastases than those with HER2-negative

*Correspondence: Dr DA Yardley; E-mail: dyardley@tnonc.com

Received 9 December 2013; revised 6 March 2014; accepted 8 March 2014; published online 17 April 2014 
disease (Kallioniemi et al, 1991; Gabos et al, 2006; Pestalozzi et al, 2006; Bravo Marques, 2009; Leyland-Jones, 2009). Before the development of HER2-targeted therapies, HER2-positive breast cancer was associated with poorer patient outcomes when compared stage for stage with other breast cancer subtypes (Slamon et al, 1987; Awada et al, 2012). The introduction of HER2-targeted therapies has resulted in markedly improved clinical outcomes in both the early- and advanced-stage disease settings (Cobleigh et al, 1999; Slamon et al, 2001; Piccart-Gebhart et al, 2005; Romond et al, 2005; Geyer et al, 2006; Slamon et al, 2011; Baselga et al, 2012; Romond et al, 2012; Verma et al, 2012; Swain et al, 2013), with outcomes in HER2-positive metastatic breast cancer (MBC) similar to those of patients with HER2negative disease (Dawood et al, 2010a). It was recently reported that the median overall survival (OS) in a cohort of patients with HER2-positive MBC who were treated with trastuzumab between 1999 and 2005 was 3.5 years from the time of initiation of therapy in the metastatic setting (Olson et al, 2013). However, despite improved patient survival times, the majority of patients with HER2-positive MBC ultimately relapse despite HER2-targeted treatment (Gajria and Chandarlapaty, 2011).

Biomarkers with the potential to predict decreased sensitivity, early resistance, or relapse to HER2-directed therapies may include overexpression of truncated HER2 protein $\left(\mathrm{p} 95^{\mathrm{HER} 2}\right.$ ); loss of the phosphatase and tensin homolog tumour-suppressor gene or activating mutations in the catalytic or regulatory subunits of phosphatidylinositol-3 kinase (PI3K), which is associated with upregulation of the PI3K/AKT/mTOR pathway; and overexpression of type 1 insulin-like growth factor receptor (Esteva et al, 2010). In patients with HER2-positive MBC, high levels of $\mathrm{p} 95^{\mathrm{HER} 2}$ were found to correlate with decreased progression-free survival (PFS) and OS (Sperinde et al, 2010) and in patients with HER2positive early-stage breast cancer, increased PI3K pathway activity was associated with a significantly worse OS (Jensen et al, 2012). Previously identified prognostic indicators in HER2-positive breast cancer include age, tumour size, axillary lymph node metastases, lymphovascular invasion, and the level of proliferation cell nuclear antigen (Liu et al, 2012). Predicting disease outcomes in patients with $\mathrm{MBC}$ is particularly complicated, as this is a biologically heterogeneous disease (Zidan et al, 2005) associated with variable clinical behaviour and survival times (Kennecke et al, 2010). Coupled with an incomplete understanding of the relationship between clinical characteristics and prognosis in HER2-positive $\mathrm{MBC}$, the factors that predict outcome or response to HER2targeted therapies are mostly exploratory.

Currently, data are limited regarding characteristics of longterm survivors (LTS) of HER2-positive MBC. RegistHER was a multicentre, prospective, observational, US-based cohort study of patients $(N=1023)$ with HER2-positive MBC initiated in 2003. The objective of this analysis was to identify and describe homogeneous latent classes labelled as short-term survivors (STS) and LTS in the registHER study, in relation to demographics, disease characteristics, and treatment history, using a latent class modelling (LCM) approach. Additionally, we investigated the relationship between potential prognostic factors and long-term survival in this patient population.

\section{MATERIALS AND METHODS}

Study design. All of the patients who were recruited to the registHER study had HER2-positive MBC (newly diagnosed within 6 months) at the time of enrolment and were recruited to the registHER study from community and academic settings between December 2003 and February 2006 (ClinicalTrials.gov, NCT00105456; http://www. clinicaltrials.gov/ct2/show/NCT00105456). Details of the study design, recruitment protocols, and study assessments have been described previously (Brufsky et al, 2011; Rugo et al, 2013). Previous or planned treatment with trastuzumab or any specific HER2-targeted therapy was not a requirement for enrolment, and patients received care in accordance with their physicians' standard practice, without study-specified evaluations. Upon enrolment, treatment history, sites of progressive disease, tumour response, survival, cardiac safety (grades 3-5), and any adverse events possibly related to the administration of trastuzumab were recorded. This information was updated every 3 months thereafter. In addition, the patients' demographic information, disease characteristics, history of breast cancer, history of metabolic disorders, cardiovascular disease (CVD), and cardiac safety data were collected. Cardiac safety events were defined using the Common Terminology Criteria for Adverse Events, v3.0 (National Cancer Institute, 2006), with selection based on physician opinion. No prespecified, scheduled assessments for tumour response were undertaken. Instead, tumour progression was reported by physicians according to their standard assessment schedule, judgment, and practice. The study was approved by all local institutional review boards, and all enrolled patients provided informed consent.

Statistical analysis. Statistical analyses were performed on all follow-up data for patients participating in registHER as of 15 June 2009 (database lock). The inclusion of data from 83 patients whose $\mathrm{MBC}$ diagnosis was made from 6 to -9 months before enrolment was permitted, and these data were included in all analyses. Of the 1023 patients in the registHER cohort, 22 were not reported as receiving any treatment for their $\mathrm{MBC}$ during the study, and data from these patients were therefore excluded from the analysis.

An LCM approach was used to identify one or more distinct homogeneous groups (latent classes) based on a simultaneous analysis of three response indicators: tumour response, PFS, and OS (Goodman, 1974; Vermunt 2009; Ross et al, 2012). The number of groups was determined by the Bayesian information criterion, and weights applied to the different indicators were estimated by maximum likelihood. Each patient was then assigned to the most likely group based on their posterior membership probabilities. Latent GOLD (Vermunt and Magidson, 2000) software was used for the LCM analysis.

Progression-free survival was defined as the time from MBC diagnosis to the first progression reported by the physicians' standard practice or death from any cause, whichever occurred first. Data for patients without disease progression or death as of the database lock were censored at the time of the last tumour response evaluation. OS was defined as the time from MBC diagnosis to the date of death from all causes. Data for patients without death as of the database lock were censored at the time of the last follow-up.

Baseline demographic and clinical characteristics were summarised by the two identified latent classes (STS and LTS) and the entire treated cohort. For continuous data, the number of observations, mean, s.d., median, minimum, and maximum were presented. Frequencies and percentages were calculated for categorical data. Comparability between LTS and STS was evaluated by the Wilcoxon rank-sum test for continuous data and by the chi-squared test for categorical data. When appropriate, 95\% confidence intervals (CIs) were presented.

Frequencies and percentages of first-line treatment regimens, best first-line tumour response, and grade 3-5 cardiac adverse events were calculated. Trastuzumab-based first-line regimens were defined as patients receiving $\geqslant 21$ days of trastuzumab in the firstline setting. The best first-line overall response was defined as the best response at any time during first-line treatment. Progressionfree survival and OS were analysed using the Kaplan-Meier method to estimate median PFS and corresponding 95\% CIs for 
Table 1. Baseline demographic and clinical characteristics of STS, LTS, and all treated patients

\begin{tabular}{|c|c|c|c|c|}
\hline Variable & STS $(n=757)$ & LTS $(n=244)$ & $\begin{array}{l}\text { All treated patients } \\
\qquad(N=1001)\end{array}$ & $P$-value ${ }^{a}$ \\
\hline Age at enrolment, median years (range) & $54(20-92)$ & $51(26-82)$ & $53(20-92)$ & 0.0049 \\
\hline $\begin{array}{l}<35 \text { years } \\
35-64 \text { years } \\
\geqslant 65 \text { years }\end{array}$ & $\begin{array}{c}39(5.2) \\
545(72.0) \\
173(22.9)\end{array}$ & $\begin{array}{r}9(3.7) \\
199(81.6) \\
36(14.8)\end{array}$ & $\begin{array}{c}48(4.8) \\
744(74.3) \\
209(20.9)\end{array}$ & 0.0117 \\
\hline
\end{tabular}

Sex, $n(\%)$

Female

Male

$748(98.8)$

$9(1.2)$

$243(99.6)$

$1(0.4)$

$991(99.0)$

$10(1.0)$

0.2873

Race, $n$ (\%)

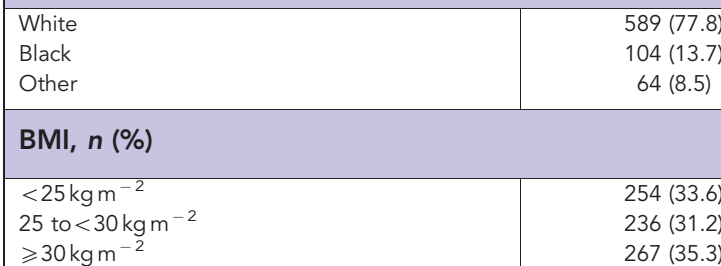

ECOG performance status at metastatic diagnosis, $n(\%)$

\begin{tabular}{|c|c|}
\hline $0-1$ & $329(43.5)$ \\
$2+$ & $48(6.3)$
\end{tabular}

Unknown/missing

$204(83.6)$
$22(9.0)$
$18(7.4)$

$793(79.2)$
$126(12.6)$

$82(8.2)$

\section{Serum albumin, $\boldsymbol{n}$ (\%)}

\begin{tabular}{|l|l}
\hline$\leqslant 3.5 \mathrm{~g} \mathrm{dl}^{-1}$ & $108(14.3)$ \\
$>3.5 \mathrm{~g} \mathrm{dl}^{-1}$ & $365(48.2)$ \\
Unknown/missing & $284(37.5)$
\end{tabular}

Unknown/missing

$76(31.1)$
$82(33.6)$
$86(35.2)$

330 (33.0)

318 (31.8)

353 (35.3)

ER/PgR status, $\boldsymbol{n}$ (\%)
$\mathrm{ER}+$ or $\mathrm{PgR}+$

ER - and PgR -

Unknown
$380(50.2)$ 284 (37.5)

\begin{tabular}{|c|c}
$385(50.9)$ & $145(59.4)$ \\
$348(46.0)$ & $86(35.2)$ \\
$24(3.2)$ & $13(5.3)$
\end{tabular}

\section{$126(51.6)$}

12 (4.9)

106 (43.4)

$45(59.4)$
$75(30.7)$

(359 (35.9)

0.1157

Site of metastatic disease at diagnosis, $n(\%)$

\begin{tabular}{|c|c}
\hline Any CNS & $62(8.2)$ \\
Bone only or bone + breast & $113(14.9)$ \\
Visceral & $466(61.6)$ \\
Node/local & $115(15.2)$ \\
Other sites & $1(0.1)$
\end{tabular}

Time to relapse after initial diagnosis, $\mathbf{n}(\%)$

$\leqslant 12$ months

$>12$ months

Stage IV at initial diagnosis (de novo MBC)

$101(13.3)$
$467(61.7)$
$189(25.0)$

34 (13.9)

$125(51.2)$

85 (34.8)

$\begin{aligned} & 10(4.1) \\ & 35(14.3) \\ & 141(57.8) \\ & 57(23.4) \\ & 1(0.4)\end{aligned}$

$455(45.5)$
$60(6.0)$

$486(48.6)$

132 (13.2)

$510(50.9)$

359 (35.9)

0.0080

0.0791

$530(52.9)$
$434(43.4)$
$37(3.7)$

0.0075

37 (3.7)

History of diabetes, $n(\%)$

\begin{tabular}{|l|c|}
\hline Yes & $65(8.6)$ \\
No/missing & $692(91.4)$ \\
\hline
\end{tabular}

History of underlying CVD (any) ${ }^{\mathrm{b}}, \mathrm{n}(\%)$

Angina

Arrhythmia

Congestive heart failure

Hypertension with complications

Myocardial infarction

Peripheral vascular disease

Other underlying cardiac disease

692 (91.4)

$13(5.3)$

$231(94.7)$

History of underlying non-cardiac comorbidities (any), n (\%)

\begin{tabular}{|l|r|r|r|r}
\hline Yes & $221(29.2)$ & $58(23.8)$ & 0.1003 \\
No/missing & $536(70.8)$ & $186(76.2)$ & $279(27.9)$ \\
\hline
\end{tabular}

Abbreviations: $\mathrm{BMI}=$ body mass index; $\mathrm{CNS}=$ central nervous system; $\mathrm{CVD}=$ cardiovascular disease; $\mathrm{ECOG}=$ Eastern Cooperative Oncology Group; $\mathrm{ER}=$ oestrogen receptor; $\mathrm{LTS}=$ long-term survivors; $\mathrm{MBC}=$ metastatic breast cancer; $\mathrm{PgR}=$ progesterone receptor; $\mathrm{STS}=$ short-term survivors.

${ }^{\mathrm{a}} \mathrm{P}$-values are from Wilcoxon two-sample test for continuous variables or chi-squared test for categorical variables for short-term vs long-term survivors.

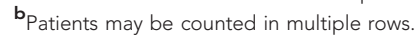


each group and overall. A logistic regression analysis on the latent class variable as a dependent variable with STS as the reference class was used to evaluate the effect of the following factors: age (age 35-64 years $v s$ age $<35$ or age $\geqslant 65$ years), race (white $v s$ non-white), Eastern Cooperative Oncology Group (ECOG) performance status, serum albumin level, tumour oestrogen receptor/progesterone receptor (ER/PgR) status, stage of disease at initial diagnosis, site of metastatic disease (adjusted using a hierarchical approach, that is, (1) central nervous system (CNS), (2) bone and/or breast, (3) visceral/other, and (4) node/local), firstline trastuzumab use, first-line taxane use, history of underlying CVD, and history of other underlying non-cardiac comorbid conditions. A sensitivity analysis evaluating the effect of these factors on OS was also performed using Cox proportional hazards (PH) analysis.

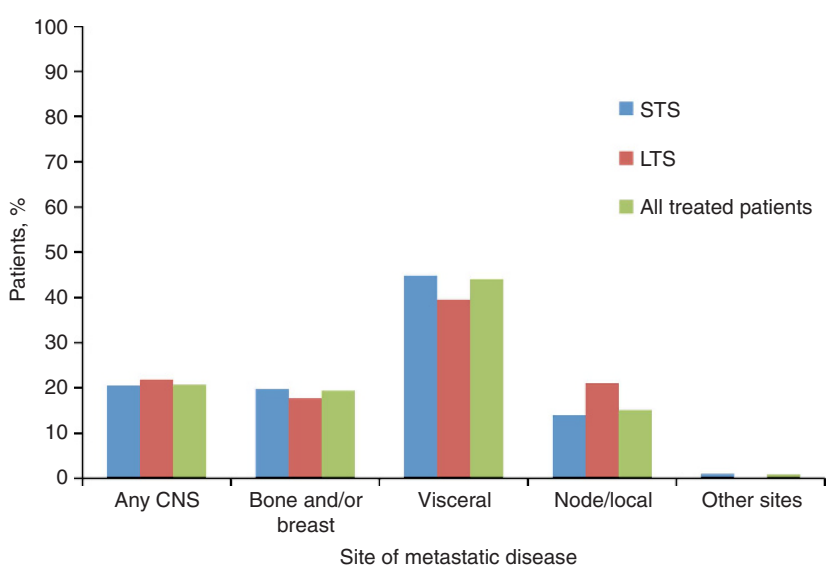

Figure 1. Site of first disease progression among short-term survivors (STS), long-term survivors (LTS), and all treated patients. Abbreviation: $\mathrm{CNS}=$ central nervous system

\section{RESULTS}

LCM outcomes. LCM was used to identify one or more distinct homogeneous LTS group(s) and one or more STS group(s), based on a simultaneous analysis of complete first-line tumour response, PFS, and OS. A two-class LCM appeared to be the best model based on the lowest Bayesian information criterion value. The first class consisted of $244(24.4 \%)$ of the 1001 patients and included $98.9 \%$ of patients (173 out of 175) who experienced a complete response (CR) as their best overall response. A total of $99.6 \%$ (243 out of 244) of patients in this group experienced CR or partial response (PR)/stable disease (SD) as their best overall response, and only $50.8 \%$ of patients within this class then later experienced progression following metastatic disease; therefore, this group was named the 'LTS latent class'. The second patient group, consisting of $757(75.6 \%)$ patients, was termed the 'STS latent class'.

Patient characteristics. Baseline demographic and clinical characteristics for STS and LTS who were followed until death, withdrawal, or until database lock are shown in Table 1. There was a statistically significant difference in median age at enrolment between the two classes (51 years in LTS vs 54 years in STS; $P=0.0049$ ). LTS and STS were similar in terms of the distribution of obese patients (body mass index $\geqslant 30$ ) and history of diabetes. The proportion of non-white patients among LTS was lower than in STS (16.4\% vs $22.2 \%$, respectively). LTS were also more likely to have $\mathrm{ER}+$ or $\mathrm{PgR}+$ disease than STS $(59.4 \%$ vs $50.9 \%$, respectively) and a lower rate of underlying CVD (15.6\% vs 19.9\%, respectively). More specifically, patients within the LTS latent class had lower rates of congestive heart failure, hypertension with complications, arrhythmia, and other underlying cardiac disease than patients in the STS class (see Table 1), although these differences were not statistically significant.

Table 2. Treatment patterns before first disease progression

\begin{tabular}{|c|c|c|c|}
\hline Treatment, n (\%) & STS $(n=757)$ & LTS $(n=244)$ & $\begin{array}{l}\text { All treated patients } \\
\qquad(N=1001)\end{array}$ \\
\hline First-line trastuzumab-based regimens ${ }^{a}$ & $n=613(81.0)$ & $n=228(93.4)$ & $n=841(84.0)$ \\
\hline $\begin{array}{l}\text { With chemotherapy only } \\
\text { With hormonal therapy only } \\
\text { With chemotherapy and hormonal therapy } \\
\text { Trastuzumab alone }\end{array}$ & $\begin{array}{l}436(71.1) \\
35(5.7) \\
93(15.2) \\
49(8.0)\end{array}$ & $\begin{array}{l}130(57.0) \\
15(6.6) \\
72(31.6) \\
11(4.8)\end{array}$ & $\begin{array}{c}566(67.3) \\
50(5.9) \\
165(19.6) \\
60(7.1)\end{array}$ \\
\hline First-line non-trastuzumab regimens & $n=144(19.0)$ & $n=16(6.6)$ & $n=160(16.0)$ \\
\hline $\begin{array}{l}\text { Chemotherapy only } \\
\text { Hormonal therapy only } \\
\text { Chemotherapy and hormonal therapy } \\
<21 \text { days of trastuzumab alone }\end{array}$ & $\begin{aligned} & 72(50.0) \\
& 53(36.8) \\
& 8(5.6) \\
& 11(7.6)\end{aligned}$ & $\begin{array}{l}7(43.8) \\
4(25.0) \\
5(31.3) \\
0\end{array}$ & $\begin{array}{l}79(49.4) \\
57(35.6) \\
13(8.1) \\
11(6.9)\end{array}$ \\
\hline \multicolumn{4}{|l|}{ Duration of trastuzumab in first line } \\
\hline $\begin{array}{l}\text { None or }<21 \text { days } \\
21 \text { days to } 4 \text { months } \\
>4-8 \text { months } \\
>8-15 \text { months } \\
>15 \text { months }\end{array}$ & $\begin{array}{r}144(19.0) \\
179(23.6) \\
193(25.5) \\
164(21.7) \\
77(10.2)\end{array}$ & $\begin{aligned} 16 & (6.6) \\
7 & (2.9) \\
27 & (11.1) \\
45 & (18.4) \\
149 & (61.1)\end{aligned}$ & $\begin{array}{l}160(16.0) \\
186(18.6) \\
220(22.0) \\
209(20.9) \\
226(22.6)\end{array}$ \\
\hline First-line treatment with chemotherapy & $n=609(80.4)$ & $n=214(87.7)$ & $n=823(82.2)$ \\
\hline $\begin{array}{l}\text { Taxane } \\
\text { Anthracyclines } \\
\text { Capecitabine }\end{array}$ & $\begin{array}{l}404(66.3) \\
38(6.2) \\
56(9.2)\end{array}$ & $\begin{array}{l}169(79.0) \\
14(6.5) \\
21(9.8)\end{array}$ & $\begin{array}{c}573(69.6) \\
52(6.3) \\
77(9.4)\end{array}$ \\
\hline Any lapatinib treatment after MBC diagnosis & $172(22.7 \%)$ & $38(15.6 \%)$ & $210(21.0 \%)$ \\
\hline
\end{tabular}


Although all patients enrolled in the study had stage IV MBC, at initial diagnosis a greater proportion of the LTS group had stage IV (de novo) disease than the STS group (34.8\% vs $25.0 \%)$. The distribution of site of metastatic disease at diagnosis was similar, with visceral sites being the most common and CNS being the least common; however, fewer LTS presented with CNS metastases compared with STS $(4.1 \%$ vs $8.2 \%$, respectively), and a greater proportion of LTS had node/local metastasis vs STS $(23.4 \%$ vs 15.2\%) (see Table 1; Figure 1).

Treatment patterns for $\mathrm{MBC}$ before first disease progression. First-line treatment patterns are defined as the therapeutic agents that patients received after $\mathrm{MBC}$ diagnosis and before first disease progression, and these may have been given either sequentially or concurrently. First-line trastuzumab use was higher in LTS (228 out of $244 ; 93.4 \%)$ than in STS (613 out of 757; 81.0\%). Among patients who received chemotherapy as first-line treatment, LTS were more likely to receive a taxane (169 out of $214 ; 79.0 \%)$ compared with STS (404 out of $609 ; 66.3 \%$ ), while anthracycline use was similar between these patient groups $(6.5 \%$ vs $6.2 \%$, respectively). Among those who received trastuzumab-based firstline treatment, LTS were more likely to receive hormonal therapy (15 out of $228 ; 6.6 \%$ ) and combined chemotherapy/hormonal therapy (72 out of $228 ; 31.6 \%$ ) compared with STS (35 out of 613; $5.7 \%$ and 93 out of $613 ; 15.2 \%$, respectively) and less likely to receive chemotherapy and trastuzumab alone (Table 2).

Clinical outcomes. Before database lock, 15.2\% of LTS had died compared with $65.3 \%$ of STS (Table 3 ). On average, LTS survived significantly longer without progressive disease than STS (median PFS, 37.2 months (95\% CI: 32.9-40.5) vs 7.3 months (95\% CI: 6.8-8.0) (Figure 2A). The median OS in STS was 27.2 months (95\% CI: 25.4-29.3) but was non-estimable (NE) in LTS because the median OS was not reached (Figure 2B). The proportion of patients achieving physician-assessed first-line CR was much higher in LTS than in STS (70.9\% vs $0.3 \%$, respectively), and as a consequence, the proportion of patients achieving PR/SD was lower in LTS than in STS (28.7\% vs 68.7\%, respectively) (see Table 3). The time between MBC diagnosis and achieving $\mathrm{CR} / \mathrm{PR} / \mathrm{SD}$ was longer in LTS, with $52.7 \%$ of LTS achieving CR/PR/SD in $<6$ months compared with $91.0 \%$ of STS (see Table 3). The proportion of patients with disease progression was lower for LTS than for STS (50.8\% vs $91.4 \%$ respectively). Although the distribution of metastasis to different body sites was similar between the two patient classes, the incidence of any CNS event was lower among LTS than among STS (18.9\% vs $43.3 \%$, respectively).

Cardiac safety outcomes. The incidence of any cardiac safety event (grades $\geqslant 3$ ) was slightly lower in LTS $(4.1 \%)$ than in STS (7.1\%) (Supplementary Table 1). Left ventricular dysfunction was the most prevalent cardiac adverse event in both LTS $(2.0 \%)$ and STS $(2.0 \%)$.

Factors associated with short-term survival. Prognostic factors associated with the probability of short-term survival as an outcome were assessed using logistic regression analysis (Figure 3). Factors significantly associated with increased odds that a patient was classified as STS were older age at enrolment $\left(\geqslant 65\right.$ years), non-white race, serum albumin $\left(\leqslant 3.5 \mathrm{~g} \mathrm{dl}^{-1}\right)$, recurrent $\mathrm{MBC}$, and metastasis to the CNS. Conversely, factors associated with increased odds that a patient was classified as LTS included $\mathrm{ER}+$ or $\mathrm{PgR}+$ disease, metastasis to bone and/or breast or node/local sites ( $v s$ visceral/other metastasis), first-line

\begin{tabular}{|c|c|c|c|c|}
\hline Parameter & Category/statistics & STS $(n=757)$ & LTS $(n=244)$ & $\begin{array}{l}\text { All treated patients } \\
\qquad(N=1001)\end{array}$ \\
\hline Number of deaths & $\begin{array}{c}n(\%) \\
\text { Due to progression } \\
\text { Other }\end{array}$ & $\begin{array}{c}494(65.3) \\
458(92.7) \\
36(7.3)\end{array}$ & $\begin{array}{c}37(15.2) \\
34(91.9) \\
3(8.1)\end{array}$ & $\begin{array}{c}531(53.0) \\
492(92.7) \\
39(7.3)\end{array}$ \\
\hline PFS since metastatic diagnosis (months) & Median $(95 \% \mathrm{Cl})$ & $7.3(6.8-8.0)$ & $37.2(32.9-40.5)$ & $10.2(9.4-11.0)$ \\
\hline Number of patients with first progression of disease & $n(\%)$ & $692(91.4)$ & $124(50.8)$ & $816(81.5)$ \\
\hline OS since metastatic diagnosis (months) & Median $(95 \% \mathrm{Cl})$ & $27.2(25.4-29.3)$ & $\mathrm{NE}$ & $35.9(32.8-39.5)$ \\
\hline \multicolumn{5}{|l|}{ Best first-line response, $n(\%)$} \\
\hline & $\begin{array}{c}\text { CR } \\
\text { PR/SD } \\
\text { Unable to evaluate } \\
\text { No assessment }\end{array}$ & $\begin{array}{c}2(0.3) \\
520(68.7) \\
20(2.6) \\
215(28.4)\end{array}$ & $\begin{array}{c}173(70.9) \\
70(28.7) \\
1(0.4) \\
0\end{array}$ & $\begin{array}{c}175(17.5) \\
590(58.9) \\
21(2.1) \\
215(21.5)\end{array}$ \\
\hline \multirow[t]{2}{*}{ Time between $\mathrm{CR}$ and MBC diagnosis, $n(\%)$} & & $n=2$ & $n=173$ & $n=175$ \\
\hline & $\begin{array}{c}\leqslant 6 \text { months } \\
6 \text { to } \leqslant 12 \text { months } \\
12 \text { to } \leqslant 18 \text { months } \\
18 \text { to } \leqslant 24 \text { months } \\
>24 \text { months }\end{array}$ & $\begin{array}{c}2(100.0) \\
0 \\
0 \\
0 \\
0\end{array}$ & $\begin{array}{c}69(39.9) \\
52(30.1) \\
22(12.7) \\
14(8.1) \\
16(9.2)\end{array}$ & $\begin{array}{c}71(40.6) \\
52(29.7) \\
22(12.6) \\
14(8.0) \\
16(9.1)\end{array}$ \\
\hline \multirow[t]{2}{*}{ Time between CR/PR/SD and MBC diagnosis, $n(\%)$} & & $n=522$ & $n=243$ & $n=765$ \\
\hline & $\begin{array}{c}\leqslant 6 \text { months } \\
6 \text { to } \leqslant 12 \text { months } \\
12 \text { to } \leqslant 18 \text { months } \\
18 \text { to } \leqslant 24 \text { months } \\
>24 \text { months }\end{array}$ & $\begin{array}{c}475(91.0) \\
45(8.6) \\
2(0.4) \\
0 \\
0\end{array}$ & $\begin{array}{c}128(52.7) \\
59(24.3) \\
23(9.5) \\
14(5.8) \\
19(7.8)\end{array}$ & $\begin{array}{c}603(78.8) \\
104(13.6) \\
25(3.3) \\
14(1.8) \\
19(2.5)\end{array}$ \\
\hline
\end{tabular}

Abbreviations: $\mathrm{Cl}=$ confidence interval; $\mathrm{CR}=$ complete response; $\mathrm{LTS}=$ long-term survivors; $\mathrm{MBC}=$ metastatic breast cancer; $\mathrm{NE}=$ non-estimable; $\mathrm{OS}=$ overall survival; $\mathrm{PFS}=$ progression-free survival; PR, partial response; $\mathrm{SD}=$ stable disease; $\mathrm{STS}=$ short-term survivors. 
trastuzumab use, and first-line taxane use. Prognostic factors associated with OS in all the treated patients were also assessed using Cox PH analysis (Figure 4). All of the factors that were associated with increased odds that a patient fell in the STS class in

A

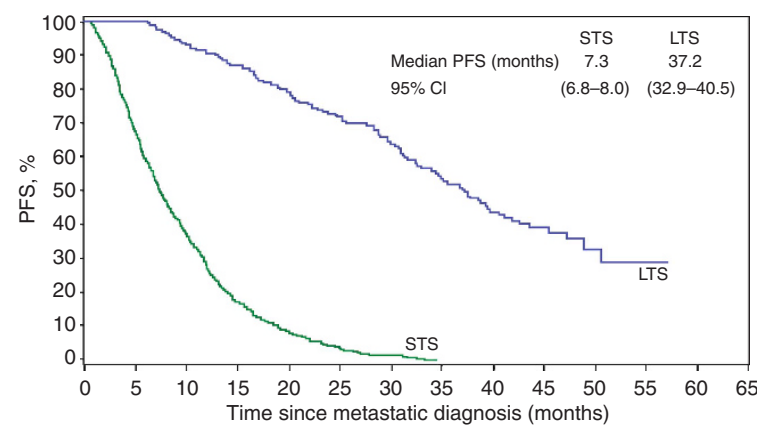

Number at risk

$\begin{array}{lllllllllllllll}\text { STS } & 752 & 494 & 269 & 119 & 58 & 23 & 8 & 0 & 0 & 0 & 0 & 0 & 0 & 0\end{array}$

$\begin{array}{lllllllllllllll}\text { LTS } & 238 & 238 & 220 & 203 & 181 & 159 & 135 & 101 & 59 & 30 & 9 & 1 & 0 & 0\end{array}$

B

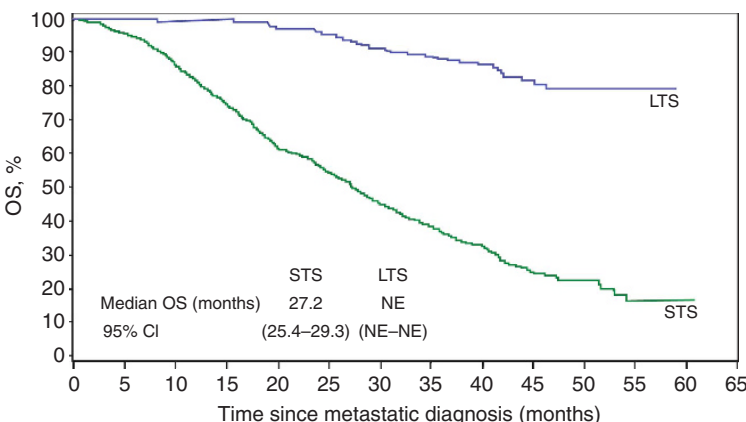

Number at risk

$\begin{array}{lllllllllllllll}\text { STS } & 757 & 715 & 633 & 525 & 417 & 357 & 284 & 299 & 146 & 63 & 21 & 7 & 1 & 0\end{array}$

LTS $\quad \begin{array}{llllllllllllll}244 & 244 & 241 & 238 & 231 & 218 & 199 & 189 & 119 & 66 & 27 & 7 & 0 & 0\end{array}$

Figure 2. Kaplan-Meier estimates of progression-free survival (A) and overall survival (B) of the short-term survivor (STS) and long-term survivor (LTS) latent classes. Abbreviations: $\mathrm{Cl}=$ confidence interval; $\mathrm{NE}=$ not estimable; $\mathrm{OS}=$ overall survival; $\mathrm{PFS}=$ progression-free survival. the logistic regression analysis were also associated with an increased risk of mortality in the Cox $\mathrm{PH}$ analysis. However, in contrast to the logistic regression analysis, in the Cox $\mathrm{PH}$ model, an ECOG performance status of $2+$ was associated with an increased risk of mortality (hazard ratio (HR), 2.022, 95\% CI: 1.434-2.851).

\section{DISCUSSION}

Prolonged, relapse-free survival has previously been documented in a small subset $(\sim 2-3 \%)$ of MBC patients, regardless of HER2 status (Greenberg et al, 1996; Kobayashi et al, 2012); however, there is a paucity of data characterising long-term survival within the HER2-positive MBC population. In our study, baseline demographic and clinical characteristics in the LTS and STS patient cohorts classified by LCM were generally similar, although there were notable exceptions, suggesting that biological differences exist between these groups. For example, LTS were less likely to have ER/PgR-negative disease, which is consistent with previous studies demonstrating that patients with HER2-positive, ER/PgRnegative tumours have a poor prognosis (Carey et al, 2006; Largillier et al, 2008; Onitilo et al, 2009). However, this is in contrast with recent accumulating evidence that ER/PgR-positivity may confer a risk of late recurrence, which may not be captured within the follow-up time period of standard clinical trials. Another difference was the lower proportion of non-white patients in the LTS compared with the STS. Although socioeconomic factors and access to care may contribute to racial differences in the stage of breast cancer at diagnosis and subsequent treatment, underlying biological differences in breast cancer phenotypes between African-American and European-American women, irrespective of HER2 status, have previously been documented (Amend et al, 2006). Black race has previously been associated with poor prognosis and lower survival rates (Ooi et al, 2011; Sparano et al, 2012; Rugo et al, 2013), and this difference in survival persists following adjustment for socioeconomic factors (Newman, 2005; Du et al, 2011). In addition, a greater proportion of the LTS had stage IV disease at initial diagnosis (i.e., de novo metastatic disease) compared with STS and may be due to effects of

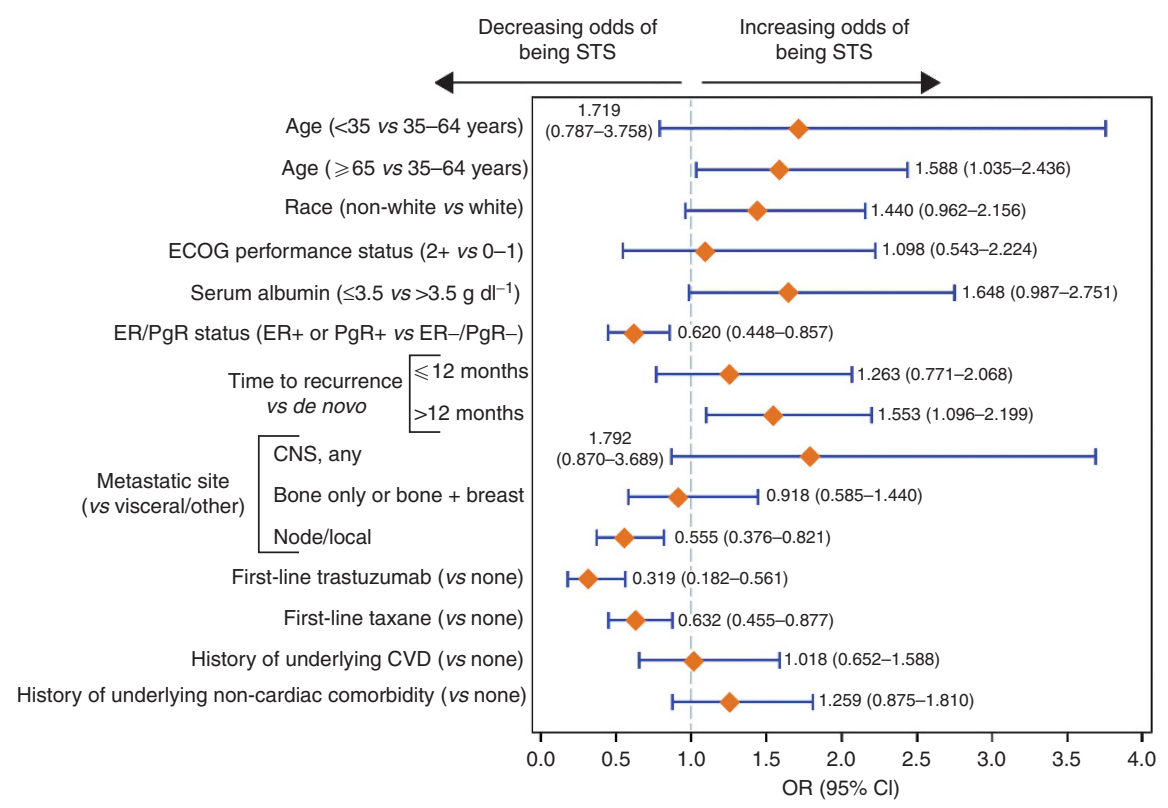

Figure 3. Logistic regression analysis examining prognostic factors associated with short-term survivors (STS). Abbreviations: $\mathrm{Cl}=$ confidence interval; CNS = central nervous system; CVD = cardiovascular disease; ECOG = Eastern Cooperative Oncology Group; ER=oestrogen receptor; $\mathrm{PgR}=$ progesterone receptor; $\mathrm{OR}=$ odds ratio. 


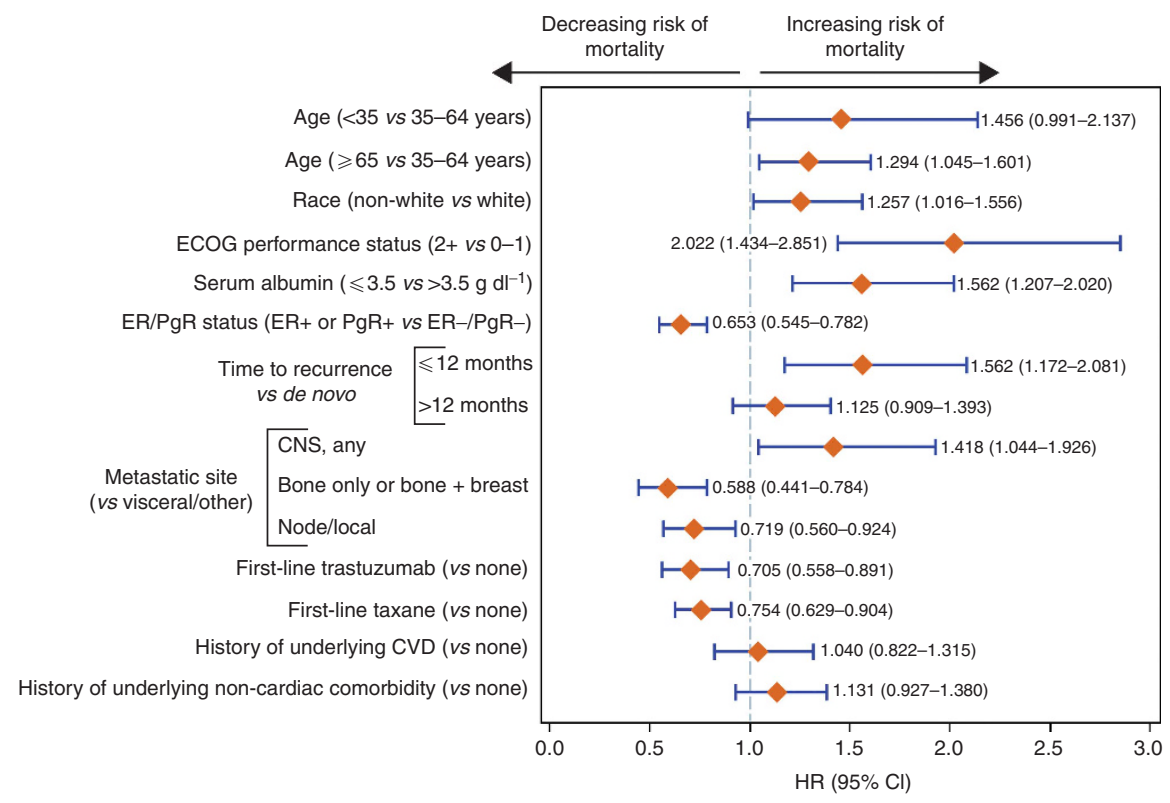

Figure 4. Cox proportional hazards model for overall survival. Abbreviations: $\mathrm{Cl}=$ confidence interval; $\mathrm{CNS}=$ central nervous system; $\mathrm{CVD}=$ cardiovascular disease; $\mathrm{ECOG}=$ Eastern Cooperative Oncology Group; $\mathrm{ER}=$ oestrogen receptor; $\mathrm{HR}=$ hazard ratio; PgR= progesterone receptor.

previous drug exposure. This is consistent with results from a separate analysis from registHER comparing outcomes in patients with de novo vs recurrent $\mathrm{MBC}$ at initial diagnosis, which demonstrated that patients with de novo $\mathrm{MBC}$ had longer median OS than patients with recurrent MBC (Yardley et al, 2014).

Analysis of treatment patterns in LTS and STS found that LTS were more likely to have undergone first-line trastuzumab treatment (93.4\% vs $81.0 \%$, respectively) and were more likely to have been treated with a taxane $(79.0 \%$ vs $66.3 \%$, respectively). In addition, LTS were twice as likely to have been treated with a combination of trastuzumab, chemotherapy, and hormones as STS $(31.6 \%$ vs $15.2 \%)$. It is unclear whether these differences result from treatment effects or are simply due to 'treatment selection bias' due to the observational non-randomised nature of this study. Additionally, as biological factors may influence both outcome and physician treatment choices, it is difficult to directly correlate treatment patterns with survival.

When examining outcomes, the proportion of patients achieving a first-line CR was significantly higher in LTS than in STS (70.9\% (173 out of 244 ) vs $0.3 \%$ ( 2 out of 757 ), respectively). Additionally, the time between MBC diagnosis and achieving a response of SD or better was shorter in STS, suggesting that some intrinsic factors may result in more responsive disease that was not durable, with more rapid development of resistance; however, the exact factors are currently unknown. Likewise, PFS was significantly longer in LTS compared with STS (median PFS 37.2 months (95\% CI: 32.9-40.5) vs 7.3 months (95\% CI: 6.8-8.0), respectively). It has previously been suggested that achieving an initial CR is a prerequisite for long-term disease-free status following $\mathrm{MBC}$ diagnosis (Greenberg et al, 1996). In our analysis, 98.9\% (173 out of 175) of the patients who achieved a CR following first-line treatment were in the LTS group, suggesting that in HER2-positive MBC CR to first-line therapy is strongly associated with survival and may partially account for the noted disparities in PFS between these two groups.

Prognostic factors associated with STS in our analysis were older age at enrolment ( $\geqslant 65$ years), non-white race, serum albumin $\leqslant 3.5 \mathrm{~g} \mathrm{dl}^{-1}$, recurrent disease, and metastasis to the CNS. This is consistent with multiple previous reports in both HER2-positive and in unselected patients (Lis et al, 2003;
Brunetto et al, 2010; Dawood et al, 2010b; Ooi et al, 2011; Kaufman et al, 2012; Sparano et al, 2012), including a recent retrospective analysis of 1038 women noting that age at initial diagnosis of $<50$ years and hormonal receptor-positive status were the most relevant prognostic factors for longer survival, while the development of CNS, multiple, and/or hepatic sites of metastasis were prognostic for worse survival (Largillier et al, 2008).

In this study, an LCM approach was used to identify the two homogeneous survival groups labelled as STS and LTS, rather than selecting a survival time point to define them (Yardley et al, 2012). The use of LCM in this study enabled the identification of two groups that are biologically distinct in terms of clinical features (ER/PgR status), age, race, and also disease response (longer PFS and higher CR rates). LCM allows for the identification of distinct long-term and short-term survival sub-populations without the use of an arbitrary cutoff time point. In addition, LCM utilises information from multiple response variables, and right censoring is handled in a statistically appropriate way, because posterior membership probabilities are estimated for all subjects, regardless of the number of months of follow-up. Patients were assigned to the latent class (either STS or LTS) in which they have the highest posterior membership probability, and there is uncertainty associated with this unless the membership probability is 1 . Although this uncertainty can be modelled (Vermunt, 2010), for simplicity, the latent class assignment was assumed to contain no error; therefore it is important to interpret the results with some caution.

In addition to limitations of the LCM analyses, further study limitations may have included 'confounding effects' resulting from the non-randomised and observational nature of the registHER study cohort. However, within each class the observed variables are statistically independent. This analysis may also have residual confounding owing to its inability to control for patient treatment compliance and previous treatment patterns, tumour size, and New York Heart Association Functional Classification. In addition, because patients could potentially have had a diagnosis of MBC for up to 9 months before enrolment, there is the possibility of selection bias for patients with a longer OS. The median OS for all treated patients in this study was 35.9 months; however, it has recently been reported that the median OS of HER2-positive MBC 
now exceeds 3 years (Olson et al, 2013), suggesting that patients with a longer OS have not been selected for within this population.

Currently, approaches to managing MBC focus on individualising treatment to best target the patient's as well as the tumour's clinical and molecular characteristics. Physician's awareness regarding the variability in the prognosis for patients with stage IV disease is crucial in making optimal treatment recommendations.

In addition to guiding treatment decisions, a better understanding of prognostic factors in MBC, particularly in the increasingly smaller subgroup of patients with HER2-positive disease, may lead to improved clinical trial design to evaluate new therapeutic agents and/or concurrent and sequential treatment combinations as well as dual HER2-targeting strategies. As the outcomes for HER2-positive MBC continue to improve, long-term follow-up of these patients to capture prospective treatment patterns, such as in registHER and the subsequent SystHERs registry, are required to develop prognostic models for identification of patients who may expect to experience long-term disease control and potentially curative outcomes.

\section{ACKNOWLEDGEMENTS}

The registHER study (ClinicalTrials.gov, NCT00105456) was sponsored by Genentech, Inc. Support for third-party writing assistance for this manuscript was provided by Genentech, Inc. We thank Bokai Xia and Jonathan Squire for their statistical programming expertise.

\section{CONFLICT OF INTEREST}

$\mathrm{AMB}$ and PAK have received consulting fees from Genentech Inc./ F. Hoffmann La-Roche, Ltd. DT has served in an uncompensated capacity on a steering committee and receives research funding (paid to his institution) for a registry study funded by Genentech, Inc./F. Hoffmann La-Roche, Ltd. MUY has served on an advisory board for Genentech, Inc. HSR has received research funding for her institution from Genentech, Inc. and GlaxoSmithKline; PAK has received research funding for his institution from Genentech, Inc. JM has received consulting fees from Genentech Inc. and has a financial interest in the Latent GOLD software package. BY and CQ are full-time employees of Genentech, Inc. and own stock in F. Hoffmann La-Roche Ltd. The other authors declare no conflict of interest.

\section{REFERENCES}

Amend K, Hicks D, Ambrosone CB (2006) Breast cancer in African-American women: Differences in tumor biology from European-American Women. Cancer Res 66: 8327-8330.

Awada A, Bozovic-Spasojevic I, Chow L (2012) New therapies in HER2-positive breast cancer: a major step towards a cure of the disease? Cancer Treat Rev 38: 494-504.

Baselga J, Cortés J, Kim SB, Im SA, Hegg R, Im YH, Roman L, Pedrini JL, Pienkowski T, Knott A, Clark E, Benyunes MC, Ross G, Swain SM. CLEOPATRA Study Group (2012) Pertuzumab plus trastuzumab plus docetaxel for metastatic breast cancer. $N$ Engl J Med 366: 109-119.

Bravo Marques JM (2009) Treatment of brain metastases in patients with HER2 + breast cancer. Adv Ther 26(suppl 1): S18-S26.

Brufsky AM, Mayer M, Rugo HS, Kaufman PA, Tan-Chiu E, Tripathy D, Tudor IC, Wang LI, Brammer MG, Shing M, Yood MU, Yardley DA (2011) Central nervous system metastases in patients with HER2-positive patients from registHER metastatic breast cancer: incidence, treatment, and survival in patients from registHER. Clin Cancer Res 17: 4834-4843.
Brunetto AT, Sarker D, Papadatos-Pastos D, Fehrmann R, Kaye SB, Johnston S, Allen M, De Bono JS, Swanton C (2010) A retrospective analysis of clinical outcome of patients with chemo-refractory metastatic breast cancer treated in a single institution phase I unit. Br J Cancer 103: 607-612.

Carey LA, Perou CM, Livasy CA, Dressler LG, Cowan D, Conway K, Karaca G, Troester MA, Tse CK, Edmiston S, Deming SL, Geradts J, Cheang MC, Nielsen TO, Moorman PG, Earp HS, Millikan RC (2006) Race, breast cancer subtypes, and survival in the Carolina Breast Cancer Study. JAMA 295: 2492-2502.

Cobleigh MA, Vogel CL, Tripathy D, Robert NJ, Scholl S, Fehrenbacher L, Wolter JM, Paton V, Shak S, Lieberman G, Slamon DJ (1999) Multinational study of the efficacy and safety of humanized anti-HER2 monoclonal antibody in women who have HER2-overexpressing metastatic breast cancer that has progressed after chemotherapy for metastatic disease. J Clin Oncol 17: 2639-2648.

Dawood S, Broglio K, Buzdar AU, Hortobágyi GN, Giordano SH (2010a) Prognosis of women with metastatic breast cancer by HER2 status and trastuzumab treatment: an institutional-based review. J Clin Oncol 28: 92-98.

Dawood S, Broglio K, Ensor J, Hortobágyi GN, Giordano SH (2010b) Survival differences among women with de novo stage IV and relapsed breast cancer. Ann Oncol 21: 2169-2174.

Du XL, Lin CC, Johnson NJ, Altekruse S (2011) Effects of individual-level socioeconomic factors on racial disparities in cancer treatment and survival: findings from the National Longitudinal Mortality Study, 1979-2003. Cancer 117: 3242-3251.

Eroles P, Bosch A, Perez-Fidalgo JA, Lluch A (2012) Molecular biology in breast cancer: Intrinsic subtypes and signaling pathways. Cancer Treat Rev 38: 698-707.

Esteva FJ, Yu D, Hung MC, Hortobágyi GN (2010) Molecular predictors of response to trastuzumab and lapatinib in breast cancer. Nat Rev Clin Oncol 7: 98-107.

Gabos Z, Sinha R, Hanson J, Chauhan N, Hugh J, Mackey JR, Abdulkarim B (2006) Prognostic significance of human epidermal growth factor receptor positivity for the development of brain metastasis after newly diagnosed breast cancer. J Clin Oncol 24: 5658-5663.

Gajria D, Chandarlapaty S (2011) HER2-amplified breast cancer: mechanisms of trastuzumab resistance and novel targeted therapies. Expert Rev Anticancer Ther 11: 263-275.

Geyer CE, Forster J, Lindquist D, Chan S, Romieu CG, Pienkowski T, Jagiello-Gruszfeld A, Crown J, Chan A, Kaufman B, Skarlos D, Campone M, Davidson N, Berger M, Oliva C, Rubin SD, Stein S, Cameron D (2006) Lapatinib plus capecitabine for HER2-positive advanced breast cancer. N Engl J Med 355: 2733-2743.

Goodman LA (1974) Exploratory latent structure analysis using both identifiable and unidentifiable models. Biometrika 61: 215-231.

Greenberg PA, Hortobagyi GN, Smith TL, Ziegler LD, Frye DK, Buzdar AU (1996) Long-term follow-up of patients with complete remission following combination chemotherapy for metastatic breast cancer. J Clin Oncol 14: 2197-2205.

Jensen JD, Knoop A, Laenkholm AV, Grauslund M, Jensen MB, Santoni-Rugiu E, Andersson M, Ewertz M (2012) PIK3CA mutations, PTEN, and pHER2 expression and impact on outcome in HER2-positive early-stage breast cancer patients treated with adjuvant chemotherapy and trastuzumab. Ann Oncol 23: 2034-2042.

Kallioniemi OP, Holli K, Visakorpi T, Koivula T, Helin HH, Isola JJ (1991) Association of c-erbB-2 protein over-expression with high rate of cell proliferation, increased risk of visceral metastasis and poor long-term survival in breast cancer. Int J Cancer 49: 650-655.

Kaufman PA, Brufsky AM, Mayer M, Rugo HS, Tripathy D, Yood MU, Feng S, Wang LI, Quah CS, Yardley DA (2012) Treatment patterns and clinical outcomes in elderly patients with HER2-positive metastatic breast cancer from the registHER observational study. Breast Cancer Res Treat 135: 875-883.

Kennecke H, Yerushalmi R, Woods R, Cheang MC, Voduc D, Speers CH, Nielsen TO, Gelmon K (2010) Metastatic behavior of breast cancer subtypes. J Clin Oncol 28: 3271-3277.

Kobayashi T, Ichiba T, Sakuyama T, Arakawa Y, Nagasaki E, Aiba K, Nogi H, Kawase K, Takeyama H, Toriumi Y, Uchida K, Kobayashi M, Kanehira C, Suzuki M, Ando N, Natori K, Kuraishi Y (2012) Possible clinical cure of metastatic breast cancer: lessons from our 30-year experience with oligometastatic breast cancer patients and literature review. Breast Cancer 19: $218-237$. 
Largillier R, Ferrero J-M, Doyen J, Barriere M, Namer M, Mari V, Courdi A, Hannoun-Levi JM, Ettore F, Birtwisle-Peyrottes C, Balu-Maestro C, Marcy PY, Raoust I, Lallement M, Chamorey E (2008) Prognostic factors in 1038 women with metastatic breast cancer. Ann Oncol 19: 2012-2019.

Leyland-Jones B (2009) Human epidermal growth factor receptor 2-positive breast cancer and central nervous system metastases. J Clin Oncol 27 : 5278-5286.

Lis CG, Grutsch JF, Vashi PG, Lammersfeld CA (2003) Is serum albumin an independent predictor of survival in patients with breast cancer? J Parenter Enteral Nutr 27: 10-15.

Liu AN, Sun P, Liu JN, Ma JB, Qu HJ, Zhu H, Yu CY, Zhang LM (2012) Clinicopathologic characteristics and prognostic factors in patients with operable HER-2 overexpressing breast cancer. Asian Pac J Cancer Prev 13: 1197-1201.

National Cancer Institute (2006) Common Terminology Criteria for Adverse Events v3.0 (CTCAE). Available at http://ctep.cancer.gov/ protocolDevelopment/electronic_applications/docs/ctcaev3.pdf. Accessed 18 April 2013.

Newman LA (2005) Breast cancer in African-American women. Oncologist 10(1): $1-14$.

Ooi SL, Martinez ME, Li CI (2011) Disparities in breast cancer characteristics and outcomes by race/ethnicity. Breast Cancer Res Treat 127: 729-738.

Onitilo AA, Engel JM, Greenlee RT, Mukesh BN (2009) Breast cancer subtypes based on ER/PR and Her2 expression: comparison of clinicopathologic features and survival. Clin Med Res 7: 4-13.

Olson EM, Najita JS, Sohl J, Arnaout A, Burstein HJ, Winer EP, Lin NU (2013) Clinical outcomes and treatment practice patterns of patients with HER2-positive metastatic breast cancer in the post-trastuzumab era. Breast 22: 525-531.

Pestalozzi BC, Zahrieh D, Price KN, Holmberg SB, Lindtner J, Collins J, Crivellari D, Fey MF, Murray E, Pagani O, Simoncini E, Castiglione-Gertsch M, Gelber RD, Coates AS, Goldhirsch A. International Breast Cancer Study Group (IBCSG) (2006) Identifying breast cancer patients at risk for Central Nervous System (CNS) metastases in trials of the International Breast Cancer Study Group (IBCSG). Ann Oncol 17: 935-944.

Piccart-Gebhart MJ, Procter M, Leyland-Jones B, Goldhirsch A, Untch M, Smith I, Gianni L, Baselga J, Bell R, Jackisch C, Cameron D, Dowsett M, Barrios CH, Steger G, Huang CS, Andersson M, Inbar M, Lichinitser M, Láng I, Nitz U, Iwata H, Thomssen C, Lohrisch C, Suter TM, Rüschoff J, Suto T, Greatorex V, Ward C, Straehle C, McFadden E, Dolci MS, Gelber RD. Herceptin Adjuvant (HERA) Trial Study Team (2005) Trastuzumab after adjuvant chemotherapy in HER2-positive breast cancer. N Engl J Med 353: 1659-1672.

Romond EH, Perez EA, Bryant J, Suman VJ, Geyer Jr CE, Davidson NE, Tan-Chiu E, Martino S, Paik S, Kaufman PA, Swain SM, Pisansky TM, Fehrenbacher L, Kutteh LA, Vogel VG, Visscher DW, Yothers G, Jenkins RB, Brown AM, Dakhil SR, Mamounas EP, Lingle WL, Klein PM, Ingle JN, Wolmark N (2005) Trastuzumab plus adjuvant chemotherapy for operable HER2-positive breast cancer. $N$ Engl J Med 353: $1673-1684$.

Romond E, Suman VJ, Jeong J-H, Sledge Jr GW, Geyer Jr CE, Martino S, Rastogi P, Gralow J, Swain SM, Winer E, Colon-Otero G, Hudis C, Paik S, Davidson N, Mamounas EP, Zujewski JA, Wolmark N, Perez EA. National Surgical Adjuvant Breast and Bowel Project (NSABP) Operations and Biostatistical Centers (2012) Trastuzumab plus adjuvant chemotherapy for HER2-positive breast cancer: final planned joint analysis of overall survival (OS) from NSABP B-31 and NCCTG N9831. Cancer Res 72(suppl 3): abstr S5-abstr S5.

Ross R, Galsky M, Scher H, Magidson J, Wassmann K, Lee G, Katz L, Subudhi S, Anand A, Fleisher M, Kantoff P, Oh W (2012) A whole-blood RNA transcript-based prognostic model in men with castration-resistant prostate cancer: a prospective study. Lancet Oncol 13: 1105-1113.

Ross JS, Slodkowska EA, Symmans WF, Pusztai L, Ravdin PM, Hortobágyi GN (2009) The HER-2 receptor and breast cancer: ten years of targeted anti-HER-2 therapy and personalized medicine. Oncologist 14: 320-368.
Rugo HS, Brufsky AM, Yood MU, Tripathy D, Kaufman PA, Mayer M, Yoo B, Abidoye OO, Yardley DA (2013) Racial disparities in treatment patterns and clinical outcomes in patients with HER2-positive metastatic breast cancer. Breast Cancer Res Treat 141: 461-470.

Siegel R, Naishadham D, Jemal A (2013) Cancer statistics, 2013. CA Cancer J Clin 63: 11-30.

Slamon DJ, Clark GM, Wong SG, Levin WJ, Ullrich A, McGuire WL (1987) Human breast cancer: correlation of relapse and survival with amplification of the HER-2/neu oncogene. Science 235: $177-182$.

Slamon D, Eiermann W, Robert N, Pienkowski T, Martin M, Press M, Mackey J, Glaspy J, Chan A, Pawlicki M, Pinter T, Valero V, Liu MC, Sauter G, von Minckwitz G, Visco F, Bee V, Buyse M, Bendahmane B, Tabah-Fisch I, Lindsay MA, Riva A, Crown J. Breast Cancer International Research Group (2011) Adjuvant trastuzumab in HER2-positive breast cancer. N Engl J Med 365: 1273-1283.

Slamon DJ, Leyland-Jones B, Shak S, Fuchs H, Paton V, Bajamonde A, Fleming T, Eiermann W, Wolter J, Pegram M, Baselga J, Norton L (2001) Use of chemotherapy plus a monoclonal antibody against HER2 for metastatic breast cancer that overexpresses HER2. N Engl J Med 344: 783-792.

Sparano JA, Wang M, Zhao F, Stearns V, Martino S, Ligibel JA, Perez EA, Saphner T, Wolff AC, Sledge Jr GW, Wood WC, Davidson NE (2012) Race and hormone receptor-positive breast cancer outcomes in a randomized chemotherapy trial. J Natl Cancer Inst 104: 1-9.

Sperinde J, Jin X, Banerjee J, Penuel E, Saha A, Diedrich G, Huang W, Leitzel K, Weidler J, Ali SM, Fuchs EM, Singer CF, Köstler WJ, Bates M, Parry G, Winslow J, Lipton A (2010) Quantitation of p95HER2 in paraffin sections by using a p95-specific antibody and correlation with outcome in a cohort of trastuzumab-treated breast cancer patients. Clin Cancer Res 16: 4226-4235.

Swain SM, Kim SB, Cortés J, Ro J, Semiglazov V, Campone M, Ciruelos E, Ferrero JM, Schneeweiss A, Knott A, Clark E, Ross G, Benyunes MC, Baselga J (2013) Pertuzumab, trastuzumab, and docetaxel for HER2-positive metastatic breast cancer (CLEOPATRA study): overall survival results from a randomised, double-blind, placebo-controlled, phase 3 study. Lancet Oncol 14: 461-471.

Verma S, Miles D, Gianni L, Krop IE, Welslau M, Baselga J, Pegram M, Oh DY, Diéras V, Guardino E, Fang L, Lu MW, Olsen S, Blackwell K. EMILIA Study Group (2012) Trastuzumab emtansine for HER2-positive advanced breast cancer. N Engl J Med 367: 1783-1791 (Erratum in N Engl J Med 2013; 368: 2442).

Vermunt JK (2009) Event history analysis. In: Handbook of Quantitative Methods in Psychology, Millsap R, Maydeu-Olivares A (eds), pp 658-674. Sage: London, UK.

Vermunt JK (2010) Latent class modeling with covariates: two improved three-step approaches. Political Anal 18: 450-469.

Vermunt JK, Magidson J (2000) Latent GOLD User's Guide. Statistical Innovations Inc.: Boston, MA, USA.

Yardley DA, Kaufman PA, Brufsky A, Ulcickas Yood M, Rugo H, Mayer M, Quah C, Yoo B, Tripathy D (2014) Treatment patterns and clinical outcomes for patients with de novo versus recurrent HER2-positive metastatic breast cancer. Breast Cancer Res Treat; e-pub ahead of print 6 April 2014; doi:10.1007/s10549-014-2916-8.

Yardley DA, Tripathy D, Brufsky AM, Rugo HS, Kaufman PA, Mayer M, Feng S, Abidoye O, Ulcickas Yood M (2012) Long-term survivor characteristics in HER2-positive metastatic breast cancer. J Clin Oncol 30(suppl 27): abstr 133.

Zidan J, Dashkovsky I, Stayerman C, Basher W, Cozacov C, Hadary A (2005) Comparison of HER-2 overexpression in primary breast cancer and metastatic sites and its effect on biological targeting therapy of metastatic disease. Br J Cancer 93: 552-556.

cc)(i) (2) This work is licensed under the Creative Commons cc) Attribution-NonCommercial-Share Alike 3.0 Unported License. To view a copy of this license, visit http://creativecommons. org/licenses/by-nc-sa/3.0/

Supplementary Information accompanies this paper on British Journal of Cancer website (http://www.nature.com/bjc) 